\title{
Hypokalemia in Patients With Eating Disorders Is Associated With Binge-Purge Behavior, Lower Body Mass Index, and Hypoalbuminemia Predicting Hypokalemia During Refeeding
}

Michitaka Funayama ( $\square$ mctkfnym@gmail.com )

Ashikaga Red Cross Hospital https://orcid.org/0000-0002-4473-9179

\section{Yu Mimura}

Keio University School of Medicine

\section{Taketo Takata}

Hangzhou Red Cross Hospital

Akihiro Koreki

National Hospital Organization Shimofusa Psychiatric Medical Center

\section{Satoyuki Ogino}

Kyorin University Faculty of Medicine Graduate School of Medicine Department of Neurosurgery: Kyorin Daigaku Igakubu Daigakuin Igaku Kenkyuka Noshinkei Gekagaku Bunya

\section{Shin Kurose}

Ashikaga Red Cross Hospital: Ashikaga Sekijuji Byoin

\section{Yusuke Shimizu}

Kyorin University School of Medicine

\section{Research Article}

Keywords: hypokalemia, body mass index, albumin, binge-purge behavior, refeeding

Posted Date: June 2nd, 2021

DOI: https://doi.org/10.21203/rs.3.rs-556323/v1

License: (c) (i) This work is licensed under a Creative Commons Attribution 4.0 International License. Read Full License

Version of Record: A version of this preprint was published at Journal of Eating Disorders on August 6th, 2021. See the published version at https://doi.org/10.1186/s40337-021-00452-2. 


\section{Abstract}

\section{Aim}

To identify potential mechanisms underlying hypokalemia in patients with eating disorders

\section{Background}

Hypokalemia is frequently found in patients with eating disorders and sometimes leads to life-threatening conditions. The mechanisms underlying hypokalemia have yet to be elucidated except for binge-purge behavior, although other factors, e.g., malnutrition and refeeding, are proposed to induce hypokalemia. In this study, we investigated factors associated with hypokalemia during acute treatment of patients with eating disorders.

\section{Methods}

We recruited 52 independent patients from 89 admissions with eating disorders (body mass index, $13.0 \pm$ 3.3) and analyzed serum potassium levels at admission. Similarly, 66 admissions with > 1-week hospitalization were recruited to determine the lowest potassium levels during the refeeding period. We analyzed these levels with multiple linear regression analysis with explanatory variables, including data upon admission and treatment-related indicators.

\section{Results}

A lower serum potassium level at admission and a lower nadir potassium level during refeeding were associated with a lower body mass index, hypoalbuminemia, and binge-purge behavior. Similar results were obtained when the analysis included restrictive or binge-purge types as well as the independent patient group. The lowest potassium levels during the refeeding period was observed an average of 2.5 days after admission.

\section{Conclusions}

Thus lower body mass index, hypoalbuminemia, and binge-purge behavior might predict hypokalemia among patients with eating disorders both at admission and during refeeding. Our study is the first to demonstrate that malnutrition and refeeding themselves might induce hypokalemia among patients with eating disorders. These factors might be used as indicators to guide clinical approaches for controlling serum potassium levels during refeeding.

\section{Plain English Summary}


Hypokalemia, low levels of serum potassium, in patients with eating disorders sometimes leads to lifethreatening conditions. Thus, it is of great importance to predict the risk of hypokalemia in patients with eating disorders. To date, only binge-purge behavior has been associated with hypokalemia. Our study found that hypokalemia in patients with eating disorders is associated with a lower body mass index and hypoalbuminemia (low levels of serum albumin), in addition to binge-purge behavior.

\section{Introduction}

Hypokalemia is frequently observed in patients with eating disorders [1-3]. Some patients with eating disorders may be able to adapt to severe chronic hypokalemia [4]. In other patients, however, hypokalemia can lead to life-threatening conditions, e.g., QTc-interval prolongation [5], ventricular fibrillation [6, 7], torsades de pointes [8], acute kidney injury [9], and interstitial nephritis [10,11]. Regarding mechanisms responsible for hypokalemia, binge-purge behavior and laxative/diuretic abuse are believed to induce hypokalemia $[3,12]$ via gastrointestinal fluid loss and the associated loss of renal potassium in the urine [13]. Other potential mechanisms underlying hypokalemia in patients with eating disorders include severe malnutrition and its associated low potassium intake [12,14, 15], surges in insulin that occur during the refeeding process $[1,16,17]$, and induction by hypomagnesemia $[18,19]$. However, no study has been performed to confirm these effects in a large number of patients with eating disorders except for bingepurge behavior. In particular, it is crucial for clinicians to predict the severity of hypokalemia during the refeeding period because the potassium nadir is usually observed after patients are refed, suggesting that there might be life-threatening conditions not only at admission but also during refeeding [20]. Thus, in this study, we carried out a retrospective investigation of mechanisms behind hypokalemia in patients with eating disorders by using laboratory data at admission as well as treatment-related indicators during the refeeding period.

\section{Materials And Methods}

\section{Participants}

Ethical aspects of this study were reviewed and approved by the Human Research Ethics Committee at the Ashikaga Red Cross Hospital. This study was performed after obtaining informed consent from all participants upon admission. For patients below the age of 18 years, informed parental consent was also obtained. Diagnosis was based on criteria in the ICD-10, and each patient was diagnosed by two of the three psychiatrists, each of whom is a board certified specialist for psychiatry and had $>10$ years of experience in psychiatry at the time of the study. Participants were recruited from the neuropsychiatric unit in Ashikaga Rec Cross Hospital during the period from April 2003 to March 2018, during which there were 90 admissions with eating disorders that were managed in our unit. These were categorized into the restrictive type (F50.0, anorexia nervosa) and the binge-purge type ( $F 50.2$, bulimia nervosa), again by two of the three psychiatrists. One patient was excluded because her serum albumin levels at admission, an indicator of morbidity that leads to malnutrition [21], were not examined. Thus, 89 admissions met the abovementioned criteria and were included in this study for serum potassium levels at admission. 
Consecutive admissions with recurrences of eating disorders were included as separate admissions [2224] because weight and nutritional status change with each admission [22]. In this study, among a total of 52 patients, all of whom were Japanese, 16 had two or more consecutive admissions, which added up to a total of 89 admissions.

Regarding nadir hypokalemia, admissions that involved hospitalization for $>1$ week were investigated. This is because refeeding syndrome, in particular, electrolyte imbalance, normally occurs within the first week of refeeding [23-25], and because the effect of refeeding on serum potassium levels should be taken into account in this analysis. Among a total of 70 admissions with hospitalization for $>1$ week, data from four admissions were excluded because second blood tests were not carried out within 6 days after admission for these individuals: three patients declined repeated blood tests, and one patient underwent the second blood test 8 days after admission. Thus, 66 admissions from 39 independent patients met the abovementioned criteria and were included in this study for the nadir hypokalemia level.

\section{Collection of patient information}

Electronic medical records of eligible participants were retrospectively reviewed. As outcome indicators, the following two measures were used: serum potassium levels at admission and nadir potassium levels during the first 2 weeks after admission. Period of the first 2 weeks was applied for the lowest potassium levels because electrolyte imbalance might last for more than 1 week after refeeding in some cases [23]. Explanatory variables included data at admission, i.e., age, sex, body mass index, eating disorder subtype (restrictive or binge-purge), data obtained from laboratory tests (serum albumin level, blood urea nitrogen/creatinine ratio, and serum magnesium levels), and indicators involving treatment, i.e., the rate of weight gain during the first 7 days, caloric intake, and amount of potassium administered. Classification of anorexia nervosa subtype, restrictive or binge-purge (bulimic-type), was carried out because binge-purge behavior, as well as its accompanying laxative/diuretic abuse, often contributes to lower serum potassium levels through repeated vomiting and diarrhea and its associated renal potassium loss in the urine $[3,12$, 13]. Body mass index, serum albumin level, and blood urea nitrogen/creatinine ratio were included as explanatory variables because those characteristics have been repeatedly identified as indicators for the severity of refeeding hypophosphatemia [22-24, 26, 27]. A lower body mass index reflects malnutrition itself [21] while a lower serum albumin level indicates morbidity that leads to malnutrition [21]. Backgrounds behind a higher blood urea nitrogen/creatinine ratio include dehydration, protein-energy malnutrition, the catabolic state, and elevated corticosteroid levels, all of which are closely related to the malnutrition found in patients with eating disorders [24]. Body mass index was calculated as the weight of the individual (in kilograms) divided by the square of the height of the individual (in meters). The indicators involving treatment were used because those factors might affect refeeding syndrome [24, 28]. To calculate the rate of weight gain during the first 7 days, we divided the kilograms gained during the first 7 days by the initial weight. Total caloric intake (kilocalories) refers to the average total caloric intake from day 1 through day $7[23,24]$, including both oral intake and intravenous infusion therapy. If the patient ate only half the provided $1200-\mathrm{kcal}$ meal, the actual amount of total caloric intake was reduced to $600 \mathrm{kcal}$. To accurately investigate the effect of energy intake on an individual patient depending on his or her weight, an indicator of total caloric intake per body weight was used for this analysis (total caloric intake 
divided by body weight), which is widely used for diet therapy for diabetes mellitus [29]. Potassium administration was defined as the average daily total potassium administration (intravenously and orally combined) from day 1 through day 7 (milliequivalents, $\mathrm{mEq}$ ). To better calculate the effect of potassium supplementation on refeeding syndrome, the amount of potassium administered was divided by total caloric intake, and this value was used in the statistical analysis. The same method has been applied to the amount of phosphorus administered during the refeeding period in a study on refeeding hypophosphatemia [24]. This is because intracellular movement of serum potassium and phosphorus is considered to be dependent on the reintroduction of nutrients, as it is mediated by surges in insulin [17].

A laboratory panel, including serum potassium levels, was carried out on admission. Regarding the 66 admissions used for the measurement of nadir hypokalemia, each blood test from the second examination onwards was conducted at 7:30 in the morning before breakfast. To precisely identify nadir serum potassium levels, the patients frequently underwent serial laboratory tests: 48 admissions (72.7\%) were tested on the second hospital day, $43(65.1 \%)$ on the third hospital day, $43(65.1 \%)$ on the fourth hospital day, 34 (51.5\%) on the fifth hospital day, 34 (51.5\%) on the sixth hospital day, 29 (43.9\%) on the seventh hospital day, and 28 (42.4\%) on the eighth hospital day. These patients continued to have blood tests until their serum potassium levels went up again. We note that 60 of 66 admissions (90.9\%) had the second laboratory test within $72 \mathrm{~h}$ of the first.

\section{Protocol for refeeding and potassium administration}

The initial caloric prescription for each patient was decided by individual physicians on admission, based on their assessment of the degree of malnutrition, caloric intake preceding admission, and the weight of each patient. Although caloric intake was administered mainly through oral food (meals and liquid formulas with nutrient compositions), intravenous infusion therapy was sometimes used and, less frequently, nasogastric feeding (liquid formulas with nutrient compositions) was also carried out. Normally, the total initial caloric prescription consisted of $\sim 600-1400 \mathrm{kcal} /$ day and was usually increased by $\sim 200$ kcal every day. Potassium supplementation more than $20 \mathrm{mEq}$ per day was not routinely carried out. However, it was prescribed when hypokalemia (less than $3.5 \mathrm{mEq} / \mathrm{L}$ ) was found in the laboratory test at admission or in subsequent tests. Intravenous potassium administration was carried out mainly with a normal sugar electrolyte maintenance transfusion solution (10 mEq in a $500-\mathrm{ml}$ transfusion) or an intravenous potassium infusion of $\sim 20-30 \mathrm{mEq}$ in 500-mL transfusion solution bags. In the acute phase, potassium administration was prescribed intravenously, whereas oral potassium administration was also carried out, in particular, in the subacute phase. The amount of potassium administration was generally started with 20-40 mEq per day, which was adjusted depending on the levels of serum potassium on serial laboratory tests. This procedure was similarly applied for hypophosphatemia and hypomagnesemia [28].

\section{Statistical analysis}

Serum potassium level at admission was investigated from data of 89 admissions (52 independent patients), whereas data from an additional 66 admissions (39 independent patients) with hospitalization for $>1$ week were used to determine the nadir hypokalemia during refeeding. Multiple linear regression 
analysis was used with explanatory variables, including demographics (age, sex, body mass index, and anorexia nervosa subtype, i.e., restrictive or binge-purge), laboratory data obtained at admission (serum albumin level, blood urea nitrogen to creatinine ratio), and treatment-related indicators (caloric intake, amount of potassium administered, and rate of weight gain). The number of patients with laxative/diuretic abuse was 20 according to the electronic medical records, all of whom were included in the binge-purge group, which poses a risk for multicollinearity in the multiple linear regression analysis. The exact number of those patients might have been higher because patients with eating disorders tend to hide such abuse, and a structured interview is needed to precisely investigate it. For these reasons, laxative/diuretic abuse was not included as an independent explanatory variable in this retrospective study, and it was included with the binge-purge behavior. No single variable had a correlation of $>0.52$ with other variables, indicating that all variables were relatively independent, such that all variables were included in the following analyses. Creatinine level, an indicator for renal dysfunction and its related hyperkalemia, was excluded from the explanatory variables because it was already included in the blood urea nitrogen to creatinine ratio. Indeed, there was no relationship between creatinine levels and serum potassium levels at admission $(p=0.91)$ or between creatinine levels and the nadir potassium levels during the refeeding period $(p=0.77)$.

For the analysis of serum potassium level at admission, six explanatory variables were used, including age, sex, anorexia nervosa subtype, body mass index, blood urea nitrogen to creatinine ratio, and serum albumin level, whereas the treatment-related variables (caloric intake, amount of potassium administered, and rate of weight gain) as well as the above-mentioned six explanatory variables were also used for analysis of nadir hypokalemia during the refeeding period.

Sub-analyses were also repeated using the four additional cohorts: patients with measured initial serum magnesium levels, the group of independent patients, the participants with binge-purge type, and those with restrictive type. Because serum magnesium levels were not measured during the night shift in this facility until December 2013, with the exception of certain special cases, we repeated the analyses using 56 admissions for serum potassium levels at admission and 44 admissions for nadir potassium levels, all of whom had undergone complete blood tests including determination of initial serum magnesium levels. Analyses using only independent patients were conducted because of a potential bias related to consecutive admissions. The first admission for each individual patient was included in this cohort (52 independent patients for initial serum potassium levels and 39 independent patients for nadir hypokalemia during refeeding. To take into account the potential heterogeneity among participants with eating disorders depending on the disorder subtype, we carried out separate comparisons among data for individuals with the restrictive subtype (53 admissions) and for those with the binge-purge subtype (36 admissions) for each explanatory variable using Student's $t$ test and Fisher's exact test. The above-mentioned multivariable analyses were also performed for each subtype. Given that the hallmark of refeeding syndrome is refeeding hypophosphatemia $[17,28]$, the correlation between a decrease in serum phosphorus levels and in potassium levels during refeeding was also investigated.

Excel 2010 (Microsoft, Redmond, WA, USA) with add-on Statcel 3 (OMS Ltd., Tokyo, Japan) was used for all statistical analyses. Two-tailed $p$-values are reported, and $p$-values of $<.05$ were considered statistically significant. 


\section{Results}

\section{Demographic factors, laboratory data at admission, and treatment indicators}

Table 1 shows the demographic factors, laboratory data at admission, and treatment indicators for the study group. The average age was $34.2 \pm 11.2$ years (range: 14 to 59 years). Of 89 admissions, only four $(4.5 \%)$ were male participants. No patient had medical conditions that might involve hypokalemia or hyperkalemia, including primary hyperaldosteronism, Cushing syndrome, hyperthyroidism, renal tubular acidosis, Bartter syndrome, Gitelman's syndrome, Addison's disease, or moderate or severe chronic renal disease. Likewise, none received antihypertensive drugs, mineralocorticoids, Kanzou (a traditional Chinese medicine), or insulin therapy, all of which affect serum potassium levels. Body mass index was relatively low at $13.0 \pm 3.3$ (range: 7.9-21.2). The average total caloric intake during the first 7 days was $1237 \pm 582$ $\mathrm{kcal} /$ day. Although the average serum potassium level at admission was $3.6 \pm 0.9 \mathrm{mmol} / \mathrm{l}$ (range: 1.7-5.8 $\mathrm{mmol} / \mathrm{l}$ ), there was a significant difference between subtypes (Student's t-test, $\mathrm{p}<0.01$ ): the average serum potassium level at admission for individuals with the restrictive type was $4.0 \pm 0.7 \mathrm{mmol} / \mathrm{l}$, whereas that for individuals with the binge-purge type was $3.2 \pm 0.9 \mathrm{mmol} / \mathrm{l}$. The average nadir potassium level was $3.1 \pm$ $0.7 \mathrm{mmol} / \mathrm{l}$ (range: $1.7-4.4 \mathrm{mmol} / \mathrm{l}$ ) with $3.3 \pm 0.6 \mathrm{mmol} / \mathrm{l}$ for individuals with the restrictive type and $2.9 \pm$ $0.8 \mathrm{mmol} / \mathrm{l}$ for individuals with the binge-purge type, levels that were also significantly different (Student's $\mathrm{t}$-test, $\mathrm{p}<0.01)$. The time interval between admission and nadir hypokalemia was longer for individuals with the restrictive type with $3.3 \pm 3.4$ days when compared with individuals with the binge-purge type with $1.3 \pm 3.0$ days (Student's t-test, $p<0.01$ ). In a total of 11 admissions $(16.6 \%), 10$ with the restrictive type and 1 with the binge-purge type, nadir hypokalemia was observed during the second week after admission.

\section{Serum potassium level at admission}

The multiple linear regression model showed that the binge-purge type $(p<0.001)$, serum albumin level $(p<$ $0.01)$, and body mass index $(p=0.01)$ predicted the serum potassium level at admission (Table 2$)$. This model resulted in a P-value of $<0.001$ and F-value of 7.8 , which is statistically significant, and explained $36.2 \%$ of the observed variance. When only the 57 admissions for which serum magnesium levels at admission were included, the results were similar with binge-purge type $(p<0.001)$ and body mass index $(p$ $=0.01)$ influencing the serum potassium level at admission $(P<0.001, F=9.0)$. When the analysis was repeated with only the 52 independent patients, the binge-purge type $(p=0.01)$, serum albumin level $(p=$ $0.02)$, and body mass index $(p=0.03)$ again predicted the serum potassium level at admission $(P<0.001$, $F=4.6$ ). When data from only patients with the binge-purge type were considered, the multiple linear regression model again showed that body mass index $(p=.04)$ predicted the serum potassium level at admission $(P<.01, F=4.6)$. When this analysis was repeated only with data from patients with the restrictive type, however, the model did not reach statistical significance $(p>0.05)$. In sum, the three variables, i.e., binge-purge behavior, a lower body mass index, and a lower serum albumin level, were associated with a lower serum potassium level at admission in patients with eating disorders.

\section{Nadir hypokalemia during refeeding}


The multiple linear regression model showed that the binge-purge type $(p=0.03)$, lower caloric intake $(p=$ $0.03)$, and a lower serum albumin level $(p=0.04)$ predicted a lower nadir hypokalemia during refeeding (Table 3). Although the relationship between body mass index and nadir hypokalemia was not statistically significant, body mass index has a tendency to affect the nadir potassium level $(p=0.054)$. This model resulted in a P-value of $<0.001$ and F-value of 4.8 , which is statistically significant, and explained $43.7 \%$ of the observed variance. When only the 57 admissions for which serum magnesium levels at admission were included, the results were similar with binge-purge type $(p<0.001)$, body mass index $(p=0.02)$, and caloric intake $(p=0.04)$ influencing nadir hypokalemia level $(P<0.001, F=6.0)$. When the analysis was repeated with only the 52 independent patients, the binge-purge type $(p=0.03)$ and amount of potassium administered $(p=0.03)$ were associated with the nadir hypokalemia $(P<0.01, F=3.3)$. When data from only patients with the restrictive type were considered $(P=0.02, F=2.6)$, the model showed that lower caloric intake ( $p=.04)$ predicted a lower nadir potassium level, with albumin having a tendency to affect nadir hypokalemia $(p=0.06)$. When the analysis was repeated using data from only participants with the bingepurge type, the model did not reach statistical significance $(P>0.05)$. In sum, a lower nadir potassium level during refeeding was associated mainly with the three variables binge-purge type, a lower body mass index, and a lower serum albumin level, as well as with lower caloric intake.

\section{Relationship between hypophosphatemia and hypokalemia during refeeding}

Among 66 admissions with hospitalization of $>1$ week, the extent of the decrease in the serum phosphorus level from admission to nadir hypophosphatemia was $1.1 \pm 1.4 \mathrm{mg} / \mathrm{dl}$, whereas that of the serum potassium level was $0.4 \pm 0.5 \mathrm{mmol} / \mathrm{l}$. A moderate positive correlation was found between the two electrolytes $(r=0.35, p<0.01)$. Among participants with the restrictive type, the extent of the decrease in the serum phosphorus level and in the serum potassium level was $1.2 \pm 1.7 \mathrm{mg} / \mathrm{dl}$ and $0.6 \pm 0.5 \mathrm{mmol} / \mathrm{l}$, respectively. In this group again, a moderate positive correlation was found between the two electrolytes ( $r$ $=0.33, p=0.03$ ). The extent of the decrease in the serum phosphorus level and in the serum potassium level for the binge-purge type was $1.0 \pm 1.1 \mathrm{mg} / \mathrm{dl}$ and $0.1 \pm 0.2 \mathrm{mmol} / \mathrm{l}$, respectively. The correlation between the two did not reach statistical significance $(p>0.05)$.

\section{Discussion}

Our present study showed that a lower serum potassium level at admission and a lower nadir potassium level during refeeding in patients with eating disorders were predicted by binge-purge behavior, a lower body mass index, and hypoalbuminemia. Although some of these three indicators did not reach statistical significance in the sub-analyses, this might have resulted from low statistical power, and thus these variables might reach statistical significance in a large-scale study. These findings suggest that these factors are useful for predicting hypokalemia and when considering potassium supplementation for patients with eating disorders. To our knowledge, except for binge-purge behavior, this is the first report on predictors for hypokalemia that are associated with eating disorders. 
Our study found that malnutrition and morbidity, which are represented by a lower body mass index and hypoalbuminemia, respectively, significantly contributed to hypokalemia at admission in patients with eating disorders. This was also the case with hypokalemia during refeeding in our study, which is quite similar to the fact that malnutrition and morbidity causes refeeding hypophosphatemia in patients with anorexia [22, 24, 26, 27]. In fact, there was a positive correlation between the extent of the decrease in serum potassium and phosphorus levels in our study, suggesting that reintroduction of nutrients led to the intracellular movement of serum potassium and phosphorus. This decrease in electrolytes during the refeeding period has been noted for decades. For example, Mehanna et al. (2008) [28] suggested that the insulin surge that results from glycemia during the refeeding process causes a substantial intracellular uptake of potassium and phosphorus. According to them, potassium, the major intracellular cation, is taken up into cells as the cells increase in volume and number with the change to anabolism upon refeeding and as a direct result of insulin secretion, even though potassium had been depleted as a result of malnutrition in these individuals. To our knowledge, our study is the first to demonstrate an actual decline in serum potassium during the refeeding period, as well as to clarify the basis for refeeding hypokalemia, that is, malnutrition. The extent of refeeding hypokalemia differed between the eating disorder subtypes in our present study. Whereas refeeding hypokalemia is obvious in patients with the restrictive subtype, at $0.6 \mathrm{mmol} / \mathrm{l}$, the extent of the decrease in the serum potassium level among individuals with the binge-purge subtype was small, at $0.1 \mathrm{mmol} / \mathrm{l}$. This is consistent with the short interval between admission and nadir hypokalemia among individuals in the binge-purge group when compared with those in the restrictive group in our study, for whom the serum potassium level decreased considerably during refeeding. Still, a lower serum potassium level at admission was predicted by a lower body mass index among individuals in the binge-purge group, suggesting that not only binge-purge behavior but malnutrition lead to hypokalemia even in this cohort.

The fact that a higher caloric intake during the refeeding period was associated with a higher nadir potassium level during this same time period might indicate that patients were able to take in potassium to a certain extent via their meals or liquid formulas when the composition of those nutrients included potassium. This is consistent with the findings on caloric intake for refeeding hypophosphatemia, in which a higher caloric intake was not correlated with the development of refeeding hypophosphatemia or with a decrease in the serum phosphorus level [24, 27, 30-34]. Thus, recent reports now recommend a highercalorie diet, starting at 1440-2400 kcal/day [30-34].

\section{Limitations}

Our study has several limitations that should be considered. First, we did not include laxative and/or diuretic abuse, which was present among a number of patients, as an explanatory variable. This is because patients with eating disorders often hide such abuse and because we did not use a structured interview on laxative and/or diuretic abuse with these patients. In this report, however, such abuse was found only in patients with the binge-purge subtype, and this factor is thus embedded into the explanatory variable related to the eating disorder subtype. Second, the amount of oral potassium intake was not investigated because we often allowed patients to bring their favorite food from home to increase their appetite, and the 
amount of potassium in such food was not able to be precisely calculated. Third, absence of a standardized protocol for potassium administration might represent a limitation in study design and interpretation of the data analyses. However, the actual amount of potassium supplementation was controlled for our multivariable regression analyses. Fourth, not all factors that might affect serum potassium levels were taken into account, such as metabolic acidosis due to peripheral circulatory insufficiency associated with extreme malnutrition. Fifth, although we tried to investigate serum potassium levels frequently in each patient, ideally these levels should be examined every day during the refeeding period to precisely determine the nadir serum potassium level. Sixth, although treatment-related indicators were measured during the first week, period of the first 2 weeks was applied for the lowest potassium levels. Indeed, nadir hypokalemia was observed during the second week in 11 admissions (16.6\%). This is a difficult issue to address because if 1 week was applied for nadir hypokalemia, the actual level of nadir hypokalemia was unable to be measured. It is also difficult to apply 2 week period for treatment-related indicators because patients had already been discharged from hospital within 2 weeks after admission in 8 admissions (12.1\%). Finally, the study population was not large, especially with respect to the sub-analyses based on the binge-purge or restrictive type. These issues should be addressed in future studies.

\section{Conclusions}

Despite the aforementioned limitations, our study demonstrates that a lower body mass index, hypoalbuminemia, and binge-purge behavior might predict a lower serum potassium level among patients with eating disorders. Our study is the first to demonstrate that malnutrition and refeeding themselves might induce hypokalemia among patients with eating disorders. These factors may be useful indicators for controlling serum potassium levels for inpatients with eating disorders.

\section{Declarations}

\section{ETHICS COMMITTEE APPROVAL}

Ethical aspects of this study were reviewed and approved by the Ashikaga Red Cross Hospital Human Research Ethics Committee.

\section{CONSENT TO PARTICIPATE}

This study was performed after obtaining informed consent from all participants upon admission. For the patients who were $<18$ years of age, informed consent was also obtained from that individual's parents.

\section{CONSENT FOR PUBLICATION}

Not applicable.

\section{DATA AVAILABILITY STATEMENT}


The datasets generated and/or analyzed during the current study are available from the corresponding author (MF) upon request.

\section{ROLE OF FUNDING}

The authors report that there were no sources of funding.

\section{CONFLICT OF INTEREST}

The authors report that there were no conflicts of interest.

\section{AUTHOR'S CONTRIBUTION}

MF, YM, TT, AK, SO, SK, and YS acquired case data. MF drafted the manuscript. All authors read and approved the final manuscript.

\section{ACKKNOWLEDGEMENTS}

We wish to thank the patients who participated in these studies.

\section{References}

1. Hofer M, Pozzi A, Joray M, Ott R, Hähni F, Leuenberger M, von Känel R, Stanga Z. Safe refeeding management of anorexia nervosa inpatients: an evidence-based protocol. Nutrition 2014; 30: 524530. https://doi.org/10.1016/j.nut.2013.09.019.

2. Mehler PS, Blalock DV, Walden K, Kaur S, McBride J, Walsh, Watts J. Medical findings in 1,026 consecutive adult inpatient-residential eating disordered patients. International Journal of Eating Disorders 2018; 51: 305-313. https://doi.org/10.1002/eat.22830.

3. Guinhut M, Melchior JC, Godart N, Hanachi M. Extremely severe anorexia nervosa: Hospital course of 354 adult patients in a clinical nutrition-eating disorders-unit. Clinical Nutrition 2020; S0261-5614(20): 30467-2. https://doi.org/10.1016/j.clnu.2020.09.011.

4. Bonne OB, Bloch M, Berry EM. Adaptation to severe chronic hypokalemia in anorexia nervosa: a plea for conservative management. Int J Eat Disord 1993; 13: 125-8. doi: 10.1002/1098108x(199301)13:1<125::aid-eat2260130115>3.0.co;2-4.

5. Krantz MJ, Blalock DV, Tanganyika K, Farasat M, McBride J, Mehler PS. Is QTc-Interval Prolongation an Inherent Feature of Eating Disorders? A Cohort Study. Am J Med 2020; 133: 1088-1094. e1. doi: 10.1016/j.amjmed.2020.02.015.

6. Stokke A, Julsrud J, Fosse A, Nielsen EW. A young woman with anorexia, hypokalemia and convulsion. Tidsskr Nor Laegeforen 2011; 131: 358-60. doi: 10.4045/tidsskr.09.0049.

7. Finsterer J, Stöllberger C. Recurrent aborted sudden cardiac death with seizures and rhabdomyolysis due to bulimia-induced hypokalemia: report of one case. Rev Med Chil 2014; 142: 799-802. doi: 10.4067/S0034-98872014000600016. 
8. Krahn LE, Lee J, Richardson JW, Martin MJ, O'Connor MK. Hypokalemia leading to torsades de pointes. Munchausen's disorder or bulimia nervosa? Gen Hosp Psychiatry 1997; 19: 370-7. doi: 10.1016/s0163-8343(97)00057-1.

9. Lee EY, Yoon H, Yi JH, Jung WY, Han SW, Kim HJ. Does hypokalemia contribute to acute kidney injury in chronic laxative abuse? Kidney Res Clin Pract 2015; 34: 109-12. doi: 10.1016/j.krcp.2014.10.009.

10. Yasuhara D, Naruo T, Taguchi S, Umekita Y, Yoshida H, Nozoe S. "End-stage kidney" in longstanding bulimia nervosa. Int J Eat Disord 2005; 38: 383-5. doi: 10.1002/eat.20198.

11. Choi JW, Kwon SK, Kim SM, Cho H, Lee HC, Kim HY. Interstitial Nephritis Caused by Anorexia Nervosa in Young Male; A Case Report and Literature Review. Electrolyte Blood Press 2018; 16: 15-17. doi: 10.5049/EBP.2018.16.1.15.

12. Greenfeld D, Mickley D, Quinlan DM, Roloff P. Hypokalemia in outpatients with eating disorders. Am J Psychiatry 1995; 152: 60-3. doi: 10.1176/ajp.152.1.60.

13. Cheungpasitporn W, Suksaranjit P, Chanprasert S. Pathophysiology of vomiting-induced hypokalemia and diagnostic approach. Am J Emergency Medicine 2012; 30: 384. doi:org/10.1016/j.ajem.2011.10.005.

14. Vavruk AM, Martins C, Nascimento MM, Hayashi SY, Riella MC. Association between hypokalemia, malnutrition and mortality in peritoneal dialysis patients. J Bras Nefrol 2012; 34: 349-54. doi: 10.5935/0101-2800.20120024.

15. Raza M, Kumar S, Ejaz M, Azim D, Azizullah S, Hussain A. Electrolyte Imbalance in Children With Severe Acute Malnutrition at a Tertiary Care Hospital in Pakistan: A Cross-Sectional Study. Cureus 2020; 12: e10541. Doi: 10.7759/cureus. 10541

16. Grasso S, Ferro Y, Migliaccio V, Mazza E, Rotundo S, Pujia A, Montalcini T. Hypokalemia during the early phase of refeeding in patients with cancer. Clinics (Sao Paulo) 2013; 68: 1413-5. doi: 10.6061/clinics/2013(11)05.

17. Garber AK, Sawyer SM, Golden NH, Guarda AS, Katzman DK, Kohn MR, Le Grange D, Madden S, Whitelaw M, Redgrave GW. A systematic review of approaches to refeeding hospitalized patients with anorexia nervosa. Int J Eat Disord 2016; 49: 293-310. doi:org/10.1002/eat.22482.

18. Hall RC, Hoffman RS, Beresford TP, Wooley B, Tice L, Hall AK. Refractory hypokalemia secondary to hypomagnesemia in eating disorders patients. Case Reports Psychosomatics 1988; 29: 435-8. doi: 10.1016/S0033-3182(88)72348-8.

19. Huang CL, Kuo E. Mechanism of hypokalemia in magnesium deficiency. J Am Soc Nephrol 2007; 18 : 2649-52. doi: 10.1681/ASN.2007070792.

20. Miller SJ. Death resulting from overzealous total parenteral nutrition: the refeeding syndrome revisited. Nutr Clin Pract 2008; 23: 166-71. doi: 10.1177/0884533608314538.

21. Marcason W. Should albumin and prealbumin be used as indicators for malnutrition? J Acad Nutr Diet 2017; 117: 1144. doi: 10.1016/j.jand.2017.04.018.

22. Redgrave GW, Coughlin JW, Schreyer CC, Martin LM, Leonpacher AK, Seide M, Verdi AM, Pletch A, Guarda AS. Refeeding and weight restoration outcomes in anorexia nervosa: challenging current 
guidelines. Int J Eat Disord 2015; 48: 866-73. Doi:org/10.1002/eat.22390.

23. Kameoka N, Iga J, Tamura M, Tominaga T, Kubo H, Watanabe Y, Sumitani S, Tomotake M, Ohmori T. Risk factors for refeeding hypophosphatemia in Japanese inpatients with anorexia nervosa. Int $\mathrm{J}$ Eat Disord 2016; 49: 402-6. doi:org/10.1002/eat.22472.

24. Funayama M, Mimura Y, Takata T, Koreki A, Ogino S, Kurose S. Body mass index and blood urea nitrogen to creatinine ratio predicts refeeding hypophosphatemia of anorexia nervosa patients with severe malnutrition. Journal of Eating Disorders 2021; 9: 1. doi:org/10.1186/s40337-020-00356-7.

25. Ornstein RM, Golden NH, Jacobson MS, Shenker IR. Hypophosphatemia during nutritional rehabilitation in anorexia nervosa: implications for refeeding and monitoring. J Adolesc Health 2003; 32: 83-8.

26. Golden NH, Keane-Miller C, Sainani K, Kapphahn CJ. Higher caloric intake in hospitalized adolescents with anorexia nervosa is associated with reduced length of stay and no increased rate of refeeding syndrome. J Adolesc Health 2013; 53: 573-8. doi:org/10.1016/j.jadohealth.2013.05.014.

27. Brown CA, Sabel AL, Gaudiani JL, Mehler PS. Predictors of hypophosphatemia during refeeding of patients with severe anorexia nervosa. Int J Eat Disord 2015; 48: 898-904. doi:org/10.1002/eat.22406.

28. Mehanna HM, Moledina J, Travis J. Refeeding syndrome: what it is, and how to prevent and treat it. BMJ 2008; 336: 1495-8. doi:org/10.1136/bmj.a301.

29. Morino K, Kondo K, Tanaka S, Nishida Y, Nakae S, Yamada Y, Ugi S, Fuse K, Miyazawa I, Ohi A, Nishida K, Kurihara M, Sasaki M, Ebine N, Sasaki S, Katsukawa F, Hiroshi Maegawa. Total energy expenditure is comparable between patients with and without diabetes mellitus: Clinical Evaluation of Energy Requirements in Patients with Diabetes Mellitus (CLEVER-DM) Study. BMJ Open Diabetes Res Care 2019; 7, e000648. doi:org/10.1136/bmjdrc-2019-000648 eCollection 2019.

30. Whitelaw M, Gilbertson H, Lam PY, Sawyer SM. Does aggressive refeeding in hospitalized adolescents with anorexia nervosa result in increased hypophosphatemia? J Adolesc Health 2010; 46: 577-82. doi:org/10. 1016/j.jadohealth.2009.11.207.

31. Garber AK, Michihata N, Hetnal K, Shafer MA, Moscicke AB. A prospective examination of weight gain in hospitalized adolescents with anorexia nervosa on a recommended refeeding protocol. J Adolesc Health 2012; 50: 24-9. doi:org/10.1016/j.jadohealth.2011.06.011.

32. O'Connor G, Nicholls D. Refeeding hypophosphatemia in adolescents with anorexia nervosa: a systematic review. Nutr Clin Pract 2013; 28: 358-64. doi:org/10.1177/0884533613476892.

33. Garber AK, Mauldin K, Michihata N, Buckelew SM, Shafer MA, Moscicki AB. Higher calorie diets increase rate of weight gain and shorten hospital stay in hospitalized adolescents with anorexia nervosa. J Adolesc Health 2013; 53: 579-84. doi:org/10.1016/j.jadohealth.2013.07.014.

34. Katzman DK, Garber AK, Kohn M, Golden NH. Refeeding hypophosphatemia in hospitalized adolescents with anorexia nervosa. J Adolesc Health 2014; 55: 455-7. doi:org/10.1016/j.jadohealth.2014. 06.010. 


\section{Tables}

Page 14/17 
Table 1

Demographic factors, laboratory data at admission, and treatment indicators of admissions with eating disorders $(\mathrm{N}=89)$

\begin{tabular}{|c|c|c|c|c|c|}
\hline Characteristic & & $\begin{array}{l}\text { Total } \\
\text { patients } \\
(\mathrm{N}=89)\end{array}$ & $\begin{array}{l}\text { Patients } \\
\text { with } \\
\text { restrictive } \\
\text { type }(n= \\
53)\end{array}$ & $\begin{array}{l}\text { Patients } \\
\text { with binge- } \\
\text { purge type } \\
(n=36)\end{array}$ & $\begin{array}{l}\text { P value for } \\
\text { comparisons } \\
\text { between types } \\
\text { (Student's t test) }\end{array}$ \\
\hline \multirow[t]{2}{*}{ Demographics } & Age (years) & $\begin{array}{l}34.2 \pm \\
11.2\end{array}$ & $\begin{array}{l}37.8 \pm \\
11.0\end{array}$ & $28.9 \pm 9.4$ & $<0.01$ \\
\hline & $\begin{array}{l}\text { Sex (female } \\
\text { participants) }\end{array}$ & $95.5 \%$ & $92.5 \%$ & $100 \%$ & $\begin{array}{l}0.14 \text { (Fisher's } \\
\text { exact test) }\end{array}$ \\
\hline \multirow[t]{7}{*}{$\begin{array}{l}\text { Data at } \\
\text { admission }\end{array}$} & Weight (kg) & $\begin{array}{l}33.3 \pm \\
9.0\end{array}$ & $31.6 \pm 6.4$ & $35.7 \pm 11.5$ & 0.03 \\
\hline & Body mass index & $\begin{array}{l}13.0 \pm \\
3.3\end{array}$ & $12.3 \pm 2.2$ & $14.1 \pm 4.3$ & 0.01 \\
\hline & Albumin $(\mathrm{g} / \mathrm{dl})$ & $\begin{array}{l}3.9 \pm \\
0.7\end{array}$ & $3.8 \pm 0.7$ & $4.0 \pm 0.6$ & 0.18 \\
\hline & $\begin{array}{l}\text { Blood urea } \\
\text { nitrogen/creatinine ratio }\end{array}$ & $\begin{array}{l}29.8 \pm \\
18.5\end{array}$ & $\begin{array}{l}35.3 \pm \\
20.7\end{array}$ & $21.6 \pm 10.5$ & $<0.01$ \\
\hline & $\begin{array}{l}\text { Serum potassium level } \\
(\mathrm{mmol} / \mathrm{l})\end{array}$ & $\begin{array}{l}3.6 \pm \\
0.9\end{array}$ & $4.0 \pm 0.7$ & $3.2 \pm 0.9$ & $<0.01$ \\
\hline & $\begin{array}{l}\text { Serum phosphorus level } \\
(\mathrm{mg} / \mathrm{dl})\end{array}$ & $\begin{array}{l}3.9 \pm \\
1.3\end{array}$ & $3.7 \pm 1.4$ & $4.1 \pm 1.0$ & 0.18 \\
\hline & $\begin{array}{l}\text { Serum magnesium level } \\
\text { ( } 56 \text { cases) }\end{array}$ & $\begin{array}{l}2.1 \pm \\
0.6\end{array}$ & $\begin{array}{l}2.0 \pm 0.4 \\
(36 \text { cases })\end{array}$ & $\begin{array}{l}2.4 \pm 0.8 \\
(20 \text { cases })\end{array}$ & 0.02 \\
\hline \multirow[t]{2}{*}{$\begin{array}{l}\text { Caloric intake } \\
\text { and weight } \\
\text { gain }\end{array}$} & $\begin{array}{l}\text { Total caloric intake } \\
\text { during the first } 7 \text { days } \\
\text { (kcal/day) }\end{array}$ & $\begin{array}{l}1237 \pm \\
582\end{array}$ & $\begin{array}{l}1221 \pm \\
646\end{array}$ & $1269 \pm 428$ & 0.75 \\
\hline & $\begin{array}{l}\text { Weight gain during } \\
\text { hospitalization }(\mathrm{kg})\end{array}$ & $\begin{array}{l}2.1 \pm \\
2.6\end{array}$ & $2.4 \pm 2.6$ & $1.7 \pm 2.6$ & 0.18 \\
\hline \multirow{3}{*}{$\begin{array}{l}\text { Data during } \\
\text { refeeding } \\
\text { period }^{\square 0}\end{array}$} & $\begin{array}{l}\text { Nadir serum potassium } \\
\text { level }(\mathrm{mmol} / \mathrm{l})\end{array}$ & $\begin{array}{l}3.1 \pm \\
0.7\end{array}$ & $3.3 \pm 0.6$ & $2.9 \pm 0.8$ & $<0.01$ \\
\hline & $\begin{array}{l}\text { Time interval between } \\
\text { admission and nadir } \\
\text { hypokalemia (days) }\end{array}$ & $\begin{array}{l}2.5 \pm \\
3.4\end{array}$ & $3.3 \pm 3.4$ & $1.3 \pm 3.0$ & 0.01 \\
\hline & $\begin{array}{l}\text { Intravenous potassium } \\
\text { administration during } \\
\text { the first } 7 \text { days } \\
\text { (mEq/day) }\end{array}$ & $\begin{array}{l}24.1 \pm \\
22.7\end{array}$ & $\begin{array}{l}19.2 \pm \\
13.3\end{array}$ & $33.9 \pm 34.5$ & 0.01 \\
\hline
\end{tabular}

${ }^{0}$ data from 66 admissions with hospitalization of $>1$ week, consisting of 46 restrictive and 20 bingepurge admissions 


\begin{tabular}{|c|c|c|c|c|c|}
\hline Characteristic & & $\begin{array}{l}\text { Total } \\
\text { patients } \\
(\mathrm{N}=89)\end{array}$ & $\begin{array}{l}\text { Patients } \\
\text { with } \\
\text { restrictive } \\
\text { type ( } n= \\
53)\end{array}$ & $\begin{array}{l}\text { Patients } \\
\text { with binge- } \\
\text { purge type } \\
(n=36)\end{array}$ & $\begin{array}{l}\text { P value for } \\
\text { comparisons } \\
\text { between types } \\
\text { (Student's t test) }\end{array}$ \\
\hline & $\begin{array}{l}\text { Weight gain during the } \\
\text { first } 7 \text { days }(\mathrm{kg})\end{array}$ & $\begin{array}{l}1.1 \pm \\
2.0\end{array}$ & $0.8 \pm 1.8$ & $1.9 \pm 2.0$ & 0.03 \\
\hline & $\begin{array}{l}\text { Nadir serum } \\
\text { phosphorus level } \\
\text { (mg/dl) }\end{array}$ & $\begin{array}{l}2.7 \pm \\
0.8\end{array}$ & $2.5 \pm 0.8$ & $3.2 \pm 0.7$ & $<0.01$ \\
\hline
\end{tabular}

Table 2

Multiple linear regression analysis for serum potassium level at admission among patients with eating disorders

\begin{tabular}{|lllllll|}
\hline Characteristic & p-Value & $\begin{array}{l}\text { Standard } \\
\text { beta }\end{array}$ & $\begin{array}{l}\text { Regression } \\
\text { coefficient }\end{array}$ & $\begin{array}{l}\text { Standard } \\
\text { error }\end{array}$ & $\begin{array}{l}\text { Lower 95\% } \\
\text { confidence } \\
\text { limit }\end{array}$ & $\begin{array}{l}\text { Upper 95\% } \\
\text { confidence } \\
\text { limit }\end{array}$ \\
\hline $\begin{array}{l}\text { Binge-purge } \\
\text { subtype }\end{array}$ & $7.450 \times 10^{-06}$ & -0.493 & -0.908 & 0.190 & -1.286 & -0.531 \\
\hline $\begin{array}{l}\text { Albumin } \\
\text { Body mass index }\end{array}$ & 0.008 & 0.263 & 0.353 & 0.129 & 0.097 & 0.610 \\
\hline $\begin{array}{l}\text { Blood urea } \\
\text { nitrogen/creatinine } \\
\text { ratio }\end{array}$ & 0.100 & 0.267 & 0.074 & 0.029 & 0.017 & 0.131 \\
\hline \begin{tabular}{l} 
Age \\
\hline Sex
\end{tabular} & 0.167 & 0.008 & 0.005 & -0.002 & 0.018 \\
\hline $\begin{array}{l}\text { Items with the bold formatting are statistically significant factors for a lower serum potassium level at } \\
\text { admission }\end{array}$ & 0.931 & -0.050 & -0.004 & 0.009 & -0.021 & 0.013 \\
\hline
\end{tabular}


Table 3

Multiple linear regression analysis for nadir potassium level during refeeding

\begin{tabular}{|c|c|c|c|c|c|c|}
\hline Characteristics & $\begin{array}{l}\mathrm{p}- \\
\text { Value }\end{array}$ & $\begin{array}{l}\text { Standard } \\
\text { beta }\end{array}$ & $\begin{array}{l}\text { Regression } \\
\text { coefficient }\end{array}$ & $\begin{array}{l}\text { Standard } \\
\text { error }\end{array}$ & $\begin{array}{l}\text { Lower } 95 \% \\
\text { confidence } \\
\text { limit }\end{array}$ & $\begin{array}{l}\text { Upper } 95 \% \\
\text { confidence } \\
\text { limit }\end{array}$ \\
\hline Binge-purge subtype & 0.030 & -0.273 & -0.420 & 0.188 & -0.797 & -0.043 \\
\hline Caloric intake & 0.031 & 0.251 & 0.008 & 0.004 & 0.001 & 0.015 \\
\hline Albumin & 0.041 & 0.228 & 0.247 & 0.118 & 0.010 & 0.484 \\
\hline Body mass index & 0.054 & 0.239 & 0.075 & 0.038 & -0.001 & 0.152 \\
\hline $\begin{array}{l}\text { Potassium } \\
\text { administration }\end{array}$ & 0.059 & -0.222 & -0.007 & 0.004 & -0.014 & 0.000 \\
\hline Weight gain & 0.130 & -0.172 & -0.019 & 0.012 & -0.043 & 0.006 \\
\hline Sex & 0.650 & 0.053 & 0.217 & 0.477 & -0.739 & 1.173 \\
\hline Age & 0.657 & -0.053 & -0.004 & 0.008 & -0.020 & 0.013 \\
\hline $\begin{array}{l}\text { Blood urea } \\
\text { nitrogen/creatinine } \\
\text { ratio }\end{array}$ & 0.661 & 0.054 & 0.002 & 0.004 & -0.007 & 0.011 \\
\hline
\end{tabular}

